\title{
Pragmatic cluster randomised trial of a free telephone-based health coaching program to support women in managing weight gain during pregnancy: the Get Healthy in Pregnancy Trial
}

Vanessa Clements ${ }^{1}$, Kit Leung ${ }^{2}$, Santosh Khanal ${ }^{3^{*}}$, Jane Raymond ${ }^{1}$, Michelle Maxwell ${ }^{4}$ and Chris Rissel $^{3}$

\begin{abstract}
Background: Excessive gestational weight gain can result in poor maternal and child health outcomes. Estimates from single studies indicate the prevalence of excessive gestational weight gain in Australia could lie between 38 and $67 \%$. The risk of excessive weight gain can be reduced through healthy eating and exercise. We describe the rationale and methods of the Get Healthy in Pregnancy Service, a trial service which aims to support women in achieving appropriate gestational weight gain through an existing telephone-based health coaching service.

Methods/Design: This study aims to compare the effectiveness of a telephone-based health coaching program versus provision of information only in supporting pregnant women to achieve appropriate gestational weight gain. A pragmatic stratified clustered randomised controlled trial will be conducted with 710 women who present to 5 hospitals for their first antenatal appointment during the recruitment period ( $6-8$ months), have a prepregnancy body mass index (BMI) $\geq 18.50$ (healthy weight or above), are 18 years and over, singleton gestation, English speaking, have no pre-existing medical conditions that may limit their ability to exercise or require a restricted diet and are 18 weeks or less gestation. Hospitals will be randomised into one of two intervention models: a) information only; or b) information plus 10 telephone-based health coaching sessions with a university qualified coach. Both interventions will set a weight-range target with pregnant women. The women attending antenatal clinics at participating hospitals will be screened at their initial hospital appointment to assess their eligibility. Women recruited to the trial will have a number of measures recorded including anthropometrics (self-reported height and weight) and dietary and physical activity scores during and following pregnancy. These measurements will be collected at baseline (prior to 18 weeks gestation), 36 weeks gestation and 12 months post-birth.

(Continued on next page)
\end{abstract}

* Correspondence: Santosh.Khanal@sswahs.nsw.gov.au

${ }^{3}$ NSW Office of Preventive Health, Sydney, Australia

Full list of author information is available at the end of the article 
(Continued from previous page)

Discussion: This study responds to a need for an effective intervention that targets excessive gestational weight gain at a population level. This study investigates the potential for an innovative intervention combining two existing services; a free state-wide telephone-based health coaching service and hospital-based antenatal care to support pregnant women to achieve healthy weight gain during pregnancy. The use of existing services provides the potential for immediate post-study implementation. While the impacts of telephone-based lifestyle programmes have been tested in a number of settings, there are few studies which evaluate the effectiveness and acceptability of telephone support in achieving healthy gestational weight gain in association with routine antenatal care.

Trial registration: ACTRN12615000397516 (Registration date: 26 June 2014, retrospectively registered).

Keywords: Health promotion, Health coaching, Gestational weight gain, Obesity, Maternal obesity

Abbreviations: BMI, Body mass index; EGWG, Excessive gestational weight gain; GHiP, Get Healthy in Pregnancy; GHS, Get Healthy Information and Coaching Service; IOM, Institute of Medicine; NSW, New South Wales

\section{Background}

Excessive gestational weight gain (EGWG) is associated with poor maternal and infant health outcomes, including an increased risk for gestational hypertension, gestational diabetes, caesarean section, low apgar scores and infants who are born large for gestational age [1-4]. There is also an increased likelihood of postpartum obesity in both mothers [2] and their children [5], which in turn leads to an increased risk of chronic disease later in life [6]. Risk factors for EGWG include a high prepregnancy BMI, with some studies showing that women who are overweight or obese prior to pregnancy are 2-6 times more likely than women with a normal BMI to be at risk of EGWG $[7,8]$. EGWG in women of all prepregnancy BMIs can lead to a progressive weight gain which is retained over a woman's reproductive years [9].

The Institute of Medicine (IOM) gestational weight guidelines [10] were updated in 2009 and are the most frequently utilised internationally. The guidelines provide ranges of recommended weight gain for specific pre-pregnancy BMI categories, based on the least risk of adverse perinatal outcomes [11]. It has been suggested that the gestational weight gain for most women in reality exceeds the IOM recommendations $[11,12]$, and in Australia, the prevalence of EGWG has been reported as being between 38 and $67 \%$ [13, 14]. The first national guidelines for antenatal care in Australia were published in August 2013, recommending that clinicians give women advice about appropriate weight gain during pregnancy in relation to their pre-pregnancy BMI [15].

Diet and exercise are modifiable risk factors for EGWG, and a number of interventions have been trialled to reduce EGWG by changing dietary and physical activity behaviours. Evidence to date however is mixed with some interventions either not resulting in a significant decrease in EGWG or only proving effective in certain groups, such as women with a normal prepregnancy BMI $[11,16,17]$. Changes in diet and physical activity can result in lower weight gain but what is not known is the mechanism by which this is achieved.

Most reported interventions are resource-intensive in terms of face to face specialist professional support and therefore unsustainable in the long term. Simple strategies such as giving women accurate advice regarding a target gestational weight gain [18], and encouraging women to self-weigh [19] appear to be effective in some groups. As in the non-pregnant population, intensive initiatives that provide regular reminders appear to produce the most effective results [20]. It seems that these do not have to be delivered directly by clinicians; Soltani et al. [21] utilised text messaging to deliver simple regular reminders with positive results, although the study numbers were too small for statistical analysis.

A recent study by Dodd et al. [22] employing a combined telephone and face to face intervention for overweight and obese pregnant women did not find any improvements in maternal and birth outcomes compared with standard care, but their study sample was skewed towards women from high socio-economic backgrounds who are more likely to have a higher baseline for health behaviours than the general population [23]. The study also did not provide women with a target gestational weight gain or evaluate the acceptability of the service.

The process of telephone-based health coaching, delivered by qualified dietitians and exercise physiologists unrelated to the client's clinical care, is a relatively new concept for maternity care providers, although well established for patients with chronic disease [24]. It is designed to support clients through regular contact to achieve a healthier lifestyle through the use of behaviour change theory, thereby also supporting the work of time-poor clinicians. A free telephone-based health coaching, the Get Healthy Information and Coaching Service (GHS), has been available to all adults over 18 years of age in New South Wales (NSW), Australia 
since 2009. People using this service can opt to receive information only or enrol in a six month coaching program. The program consists of 10 individually tailored calls from university qualified coaches, aimed at making sustained improvements in healthy eating, physical activity and achieving or maintaining a healthy weight. Extensive evidence exists for the effectiveness of telephonebased lifestyle programs and evaluation of the GHS itself shows that participants who complete the 6 month coaching program lose an average of $3.9 \mathrm{kgs}$ and reduce their waist circumference by $5.0 \mathrm{cms}$. [25] The GHS has a considerable proportion of participants who are female (73\%) and reside outside of major cities $(40 \%)$ as well as being from lower socio-economic backgrounds [26].

\section{The NSW Get Healthy in Pregnancy Service (GHiP)}

A telephone-based service for pregnant women of New South Wales (NSW), Australia, Get Healthy in Pregnancy (GHiP), was developed in collaboration between the NSW Office of Preventive Health and NSW Kids and Families to support women to achieve appropriate gestational weight gain through health coaching. GHiP was developed as an enhancement to the GHS. Development of GHiP has been informed by evaluations of other interventions aimed at reducing EGWG with the input of an Expert Advisory Panel including midwives, obstetricians, dietitians and antenatal educators from across NSW. Pregnant women have suggested in a qualitative study in the UK that they would prefer a healthy eating service that is integrated into routine care and provides information early in their pregnancy [27]. Two potential models for the GHIP integrated with hospital antenatal care have been developed and will be compared as the two arms in this study:

- Information only - introduction of gestational weight gain recommendations by midwife at their initial hospital antenatal appointment, evidence-based factsheets and an information booklet on healthy eating, exercise and weight gain during pregnancy in line with Australian guidelines [28-30], and a single health coaching call; and

- Health coaching - introduction of gestational weight gain recommendations by midwife at their initial hospital antenatal appointment, the same factsheets and information booklet as the information only group, plus a journey booklet to record progress and up to 10 health coaching calls (8 during pregnancy, 2 post pregnancy).

Both service models commence between 12 and 22 weeks gestation. Participants receiving health coaching are offered coaching calls up until 36 weeks gestation and receive two coaching calls at 10 and 14 weeks postdelivery.

\section{Methods/Design}

\section{Aims and objectives}

This study will compare the effectiveness of a telephonebased health coaching program versus provision of information alone in supporting pregnant women to achieve appropriate gestational weight gain. Pregnant women will be stratified into pre-pregnancy healthy weight and overweight/obese groups. Given the evidence around issues related to excessive weight gain in pregnancy, a pure control group was not included in the study as it was considered inappropriate to not provide information that could be beneficial to maternal and neonatal health.

The hypothesis of the study is that, pregnant women enrolled in the coaching program will be more likely to achieve a healthy gestational weight gain during pregnancy and better maintain their pre-pregnancy weight post pregnancy. Weight-gain that is above the IOM guidelines is considered excessive gestational weightgain.

The primary objectives of the study are to:

i) Compare the differences in gestational weight gain and weight retention at 12 months post birth of participants in the health coaching and information only arms

ii) Understand the acceptability and experiences of telephone-based coaching amongst pregnant women and antenatal service providers.

As secondary objectives, the study will:

iii) Compare changes in diet (fruit, vegetable, fast food and sweetened drink intake)

iv) Assess the predictors of service participation and retention

v) Explore service usage patterns such as length of calls and preferred time

vi) Assess confidence to change

vii) Provide recommendations for program improvement.

\section{Study design}

This study employs a pragmatic stratified cluster randomised design [31] with stratification by healthy weight and overweight/obese pre pregnancy BMI.

Pregnant women in the study will be allocated to either the information only or health coaching group based on the hospital where they present for antenatal care (Fig. 1). This design was selected to obtain results that can be generalised with high external validity and utility in the real world setting. In this study, the trial environment and processes will be as close as possible to how the program would be rolled out if effective. A range of hospitals in both metropolitan and rural 


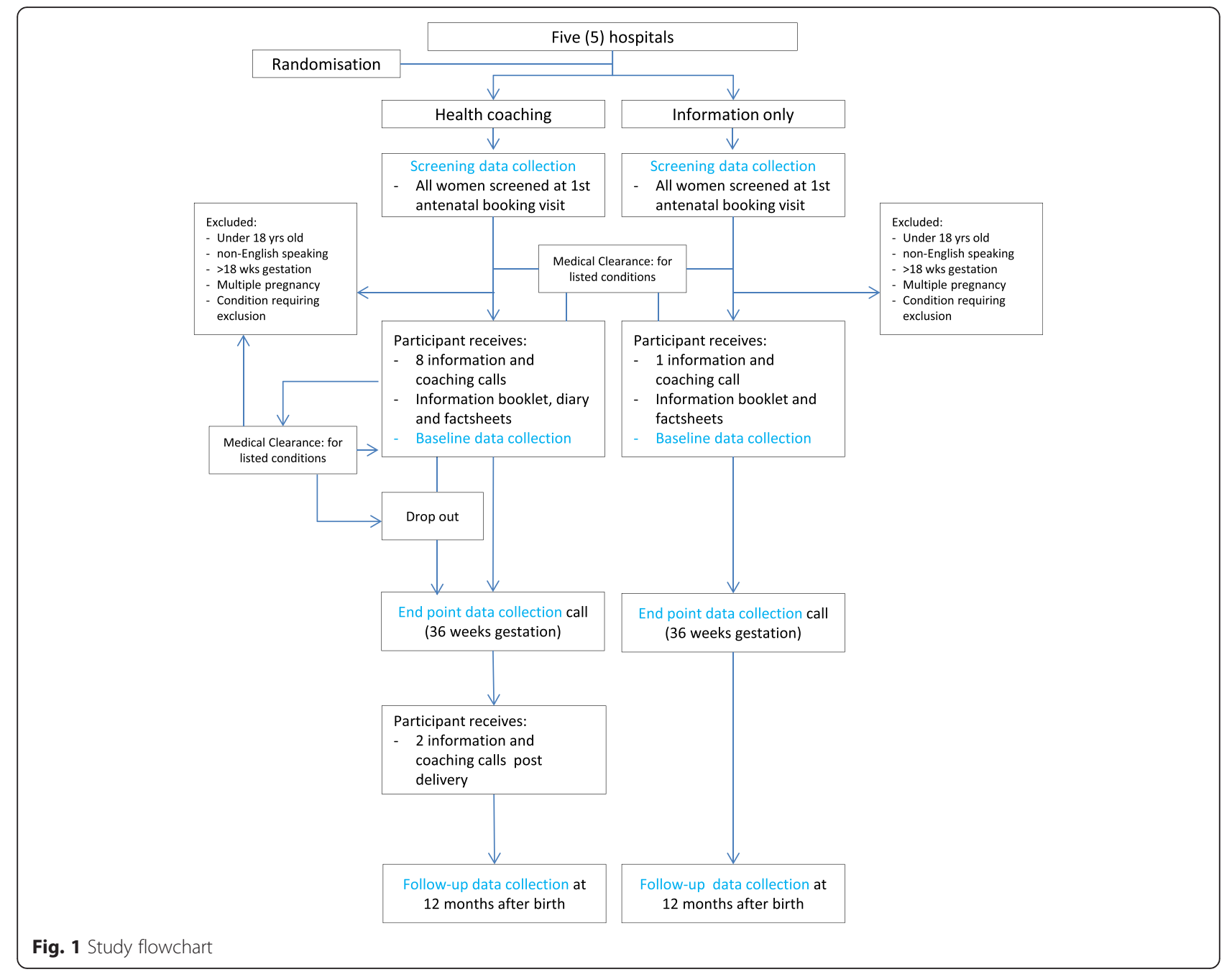

settings, of different sizes and maternity service delivery levels have been chosen to test the scalability of the intervention across the state.

Randomisation of hospitals, stratified by metropolitan and rural regions, will be undertaken using Microsoft Excel 2010@ randomisation generator. Two rural hospitals were combined into one unit for randomisation because they are in the same Local Health District and their aggregated total number of births in 2012 was similar to the total of the other rural hospital in the study. Face-to-face training will be provided, by members of the research team, to the midwives and medical officers at each site to describe the study and the program. The hospitals will develop their own processes to integrate the GHiP referral into the first antenatal appointment for pregnant women. As part of this process, hospitals in both arms will be required to include initial discussion on the importance of healthy gestational weight gain, the setting of a target weight-gain range for the woman's pregnancy (as per IOM recommendations), screening of the woman for exclusion criteria and recruitment of women following consent.

Health coaches (primarily dieticians and exercise physiologists) delivering GHiP will be provided with a day's face-to-face training by clinical experts in dietetics and maternity care, in addition to their usual training. A list of online resources to support the pregnant women will also be available to all health coaches. The clinical experts will also be available for further consultation as required.

\section{Study setting}

The study will be conducted in the antenatal clinics of five NSW hospitals of which three are rural (Orange Base, Lismore Base and Dubbo Base) and two metropolitan (Liverpool and Blacktown). Hospitals were recruited through an expression of interest process addressed to the general manager of each site in the first instance. Agreement was also obtained from the midwifery unit manager and obstetric lead of the maternity unit at each 
hospital to ensure local support prior to inclusion. All hospitals are public hospitals accounting for approximately $10 \%$ of the total births in NSW and the demographic characteristics of women attending the two metropolitan and the three rural hospitals are similar within their categories. The hospitals offer a variety of antenatal care options for women including hospitalbased, shared care with general practitioners or via community based midwifery group practices. All of these care models require women to attend the hospital for an initial antenatal appointment which usually occurs after 12 weeks of gestation.

\section{Recruitment strategies}

Pregnant women who are presenting at one of the five participating hospitals will receive a flyer with their initial appointment letter and advised that their midwife will discuss the Get Healthy in Pregnancy service and research trial with them at their first appointment. Midwives during the recruitment period will screen and assess every woman presenting for their first antenatal visit to determine eligibility to be enrolled in the study. Women eligible to participate will be offered the opportunity to participate in the trial and asked for written consent. Women who are unsure whether they participate will be contacted by a research assistant within a week and reoffered the opportunity to participate.

\section{Participants}

Participants will be 710 pregnant women who attend one of five hospitals during the recruitment period and are English speaking, 18 years and over, have a singleton pregnancy, have a gestation of 18 weeks or under and agree to participate (signed consent forms and verbal consent provided at first coaching call).

\section{Medical conditions}

An exclusion list and requirements for medical clearance (Table 1) for women with conditions that may impact their involvement was established to ensure safety of the women participating in the study. The national guidelines for consultation and referral by midwives [32] were used to identify the medical conditions for exclusion or medical clearance. For the purpose of this study, all conditions identified within the guidance as requiring referral to a medical practitioner for specialist care were

Table 1 Medical conditions for exclusion from the study or requiring clearance from a medical practitioner

\begin{tabular}{|c|c|c|}
\hline & Pre-existing conditions (at screening) & Conditions developed during the study period \\
\hline Excluded from the study & $\begin{array}{l}\text { Cardiovascular disease: } \\
\text { - Arrhythmia/palpitations; murmurs: recurrent, persistent or } \\
\text { associated with other symptoms } \\
\text { - Cardiac valve disease } \\
\text { - Cardiac valve replacement } \\
\text { - Cardiomyopathy } \\
\text { - Congenital cardiac disease } \\
\text { - Ischaemic heart disease } \\
\text { - Pulmonary hypertension } \\
\text { Endocrine: } \\
\text { - Pre-existing Type } 1 \text { diabetes } \\
\text { - Cystic fibrosis } \\
\text { - Phenylketonuria (PKU) } \\
\text { Respiratory Disease } \\
\text { - Sarcoidosis } \\
\text { Severe lung disorder }\end{array}$ & $\begin{array}{l}\text { - Fetal death in utero } \\
\text { - Small for dates }(<10 \text { th centile) } \\
\text { - Multiple pregnancy } \\
\text { - Preterm birth (<36 weeks) } \\
\text { - Rupture of membranes (<36 weeks) } \\
\text { Placental indications: } \\
\text { - Placental abruption } \\
\text { - Placenta accrete } \\
\text { - Placenta preavia } \\
\text { - Vasa Praevia }\end{array}$ \\
\hline $\begin{array}{l}\text { Medical clearance required } \\
\text { to participate }\end{array}$ & $\begin{array}{l}\text { Cardiovascular disease } \\
\text { - Hypertension } \\
\text { Neurological } \\
\text { - Epilepsy } \\
\text { Respiratory disease } \\
\text { - Asthma Moderate (women requiring daily bronchodilators } \\
\text { and steroid inhalers) } \\
\text { - Type } 2 \text { diabetes (diet/medication controlled) } \\
\text { Skeletal problems } \\
\text { - Musculo-skeletal problems } \\
\text { Previous obstetric history } \\
\text { - Previous pre-term birth } \\
\text { - Recurrent miscarriage } \\
\text { History of mental health } \\
\text { - History of mental health conditions (e.g. eating disorders) } \\
\text { Endocrine } \\
\text { - Type } 2 \text { diabetes (diet/medication controlled) } \\
\text { Gastro-intestinal } \\
\text { Coeliac Disease }\end{array}$ & $\begin{array}{l}\text { Endocrine } \\
\text { - Pre-existing Type } 2 \text { diabetes now requiring medication } \\
\text { Skeletal problems } \\
\text { - Herniated vertebral disc } \\
\text { - Symphysis pubis dysfunction } \\
\text { Cardiovascular disease } \\
\text { Chronic hypertension } \\
\text { Obstetric related } \\
\text { - Anaemia }(\mathrm{Hb}<90) \\
\text { - Fetal size small for dates } \\
\text { - Vaginal blood loss } \\
\text { - Pre-eclampsia } \\
\text { - Gestational diabetes - diet/medication controlled } \\
\text { Gestational hypertension }\end{array}$ \\
\hline
\end{tabular}


reviewed by the GHiP Expert Advisory Group with regard to the woman's ability to be able to safely modify her diet or levels of activity.

For women requiring medical clearance, the participant file will be forwarded to a medical practitioner for review. During the review the medical practitioner will be required to select from three options; clear the woman for full participation in the trial, exclude from the trial, or provide parameters within which the woman can participate (eg. restricting certain forms of physical activity or certain variations to the woman's diet).

\section{Sample size}

A total of 710 women will be recruited; 177 and 532 pregnant women with a pre-pregnancy BMI of 18.5$24.9 \mathrm{~kg} / \mathrm{m}^{2}$ (healthy range) and $\geq 25.0 \mathrm{~kg} / \mathrm{m}^{2}$ (overweight or obese range) respectively. 248 women will be recruited across the three rural hospitals with 462 recruited at metropolitan hospitals. The higher numbers in metropolitan hospitals is to reflect the larger target population in these areas.

The sample size has been calculated using previous reports of weight gain during pregnancy $[10,13,33]$ to detect a difference of $3 \mathrm{kgs}$ in gestational weight gain between intervention and control groups at $80 \%$ power. Attrition rates of $60 \%$ in the coaching arm and $30 \%$ in the information only arm are expected. These rates account for the up to $15 \%$ of women, across both arms, who start the study and go on to develop conditions during pregnancy that exclude them from further participation [34] and, allows for the perception of participant burden in the coaching arm. The relatively high attrition rate is conservative compared with other population based programs.

\section{The interventions \\ Coaching arm}

Women in the coaching arm will be enrolled in a full coaching program comprising of up to 10 calls by university qualified coaches ( 8 during pregnancy and 2 after birth). Health coaches, using behaviour change informed coaching techniques, will in their first call confirm and discuss the woman's weight range target according to the IOM guidelines, and develop personally relevant lifestyle change goals and actions for participants to achieve their target weight range. In subsequent coaching calls health coaches will ensure that no conditions have presented in the pregnancy that may require medical clearance or adapted advice, revisit goals and revise them accordingly with the participant, help maintain motivation, discuss strategies for overcoming barriers and prevent relapse of healthy behaviours. Health coaches are guided by a range of national and international guidelines for nutrition, exercise and weight-gain targets for pregnancy. The timing of calls is designed to be flexible based on participant preferences and will generally last between 15 and $25 \mathrm{~min}$. A recommended schedule for the pregnancy coaching calls will be used; three in the first 3 weeks, followed by a call every $2-4$ weeks until the end of the pregnancy with two calls post birth.

In addition, participants in the health coaching group will be provided with supportive materials including pregnancy specific factsheets on healthy eating, exercise and the benefits of healthy weight-gain during pregnancy and a general information booklet and diary for setting and tracking health goals. Women will receive usual care from their maternity clinicians during the trial with the exception to setting their weight-gain range target and general advice about gestational weight gain at their first antenatal visit with their midwife.

\section{Information only arm}

Women in the information only arm will receive a one off information and coaching session from a health coach and will receive the information materials described above (with exception of the diary). Women will receive usual care from their maternity clinicians during the trial with the exception of setting their weight-gain range target and general advice about gestational weight gain at their first antenatal visit with their midwife.

\section{Data collection \\ Quantitative}

Data for the study will be collected at baseline (prior to 18 weeks gestation), 36 weeks gestation and 12 months post-birth. Baseline, endpoint and follow up data will be self-reported by the women. These data will include validated dietary [35-37] and physical activity [38, 39] measures. Baseline and endpoint data for the coaching arm will be collected by the health coach for the coaching arm and by a research assistant for the information only arm. Coaching participants who discontinue the coaching program without withdrawing from the study will be contacted by the research assistant for their endpoint data collection. The 12 months post birth data will be collected by the research assistant.

\section{Qualitative interviews}

Semi-structured telephone interviews (Additional files 1, 2 and 3) will be conducted by three researchers experienced in qualitative data collection methods (VC, KL and JR). Interviews will be recorded using a digital recorder and transcribed by a professional transcription service. Interview guides will be used to illicit the study participants' experiences of the service, usefulness of 
program resources and suggestions for service improvement. Interviews will be conducted with the following:

(a) Up to 22 pregnant women in the coaching arm. A subset of this group will include women who actively withdraw from the coaching program.

(b) Up to 18 pregnant women in the information only arm.

(c) Up to 35 healthcare professionals (including clinic managers, midwives, doctors, and health coaches) who have contributed to the program by coordinating at the hospitals, recruiting pregnant women, providing medical clearance or delivering the service.

\section{Data analysis}

\section{Primary objectives}

All quantitative data analysis will be based on intention to treat principles. Differences between the two study groups in self-reported weight change from prepregnancy weight to weight at 36 weeks gestation and 12 months post birth will be tested using the independent samples $t$-test. The proportions of pregnant women who achieve weight gain within the recommended range and those who return to their pre-pregnancy weight 12 months post birth will be analysed using the $X^{2}$ test. The adjusted means of the BMI outcomes at 36 weeks gestation and follow up by BMI category will be compared with the pre pregnancy BMI.

Interview data will be analysed using the thematic analysis approach. The transcribed interviews will be coded by the researchers and if there is a disagreement in the classification of interview responses, the researchers will convene as a group to discuss the discrepancies and revise coding categories if needed. Once agreement is reached, themes and sub-themes will be extracted from the data. Data from the interviews will inform the provision of recommendations for program improvement.

\section{Secondary objectives}

Predictors of weight gain within the recommended range at 36 weeks of gestation will be analysed using multilevel linear mixed model. Covariance effects of hospital clusters and study arms will be incorporated into the models as random effects. Then the factors that contribute to BMI outcomes at 36 weeks will be determined with demographic variables, socio-economic status, age, pre pregnancy BMI and parity as the fixed effects.

Changes in dietary scores and confidence to change will be analysed using repeated measures analysis of variance, with the type of intervention and data collection point as between and within subject variables respectively.

Participation and retention in the service and preference for time and length of calls will be analysed using descriptive statistics with reference to the qualitative interview data where appropriate. The recommendations for service improvement will be one of the key themes in analysis of the qualitative data. The referral patterns of the hospitals will also be evaluated to assess recruitment rates with reference to the qualitative interviews with the midwives and doctors to identify the potential barriers and solutions to enhance service participation.

\section{Discussion}

This study uses a robust design in a real-life routine practice setting to add additional knowledge and understanding to the growing body of evidence around interventions to target excessive gestational weight gain. This study is rare in that it considers both process and outcomes.

The pragmatic approach to the integration of the service with routine antenatal care will facilitate recruitment into the intervention in a clinical setting under realistic conditions without compromising program fidelity or requiring additional staff. Existing state-wide services will be utilised (routine antenatal care and the NSW Get Healthy Service) to recruit women to the service and provide the telephone-based coaching. The advantage of this approach is that the 'real-world' conditions of the trial will provide information to inform a rapid implementation of the service to other hospitals in NSW.

There are however unavoidable limitations to the pragmatic approach. Recruitment into GHiP may be influenced by local variables such as the strength of leadership, the presence of clinical champions, the individual approach of the midwives and organisation of care.

Integrating telephone-based health coaching with standard maternity care is a new concept for maternity services. The findings of this population-based study will help to determine if a telephone-based health coaching and information program is effective for women in supporting them to achieve a healthy gestational weight gain. In addition the trial seeks to examine the acceptability of the service to both women and maternity care providers.

\section{Additional files}

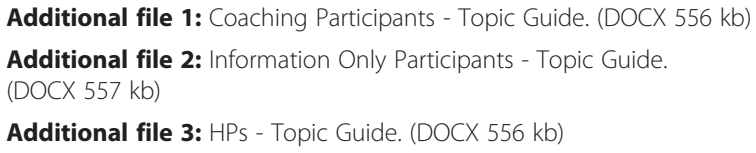

Additional file 1: Coaching Participants - Topic Guide. (DOCX 556 kb)

Additional file 2: Information Only Participants - Topic Guide. (DOCX 557 kb)

Additional file 3: HPS - Topic Guide. (DOCX $556 \mathrm{~kb}$ )

\section{Acknowledgments}

We would like to thank the midwives and medical officers at the five study sites who recruited women to the service, the clinic coordinators for the local management of the trial, Healthways staff for providing the coaching 
service, the GHiP Expert Advisory Group for clinical advice and Praveena Gunaratnam for working on the original proposal and ethics application.

\section{Funding}

The study was internally funded by the NSW Office of Preventive Health.

\section{Availability of data and material}

The screening tool and the interview guides that were developed for the study have been made available as additional files. Not applicable for data.

\section{Authors' contributions}

All authors were involved in designing and planning the program and the study including the selection of study sites. KL and SK conducted the sample size calculation and site randomisation. JR, VC, KL, and MM developed and coordinated the implementation of the GHiP program. SK and CR contributed to the data analysis plan. All authors were involved in writing the paper and had final approval of the submitted and published versions.

\section{Competing interests}

The authors declare that they have no competing interests.

\section{Consent for publication}

Not applicable.

\section{Ethics approval and consent to participate}

The study has been approved by the Human Research Ethics Committee of South Western Sydney Local Health District (Ref: HREC/14/LPOOL/131) and site specific approvals were obtained for each study site (Lismore Base Hospital, Liverpool Hospital, Blacktown Hospital, Orange Base Hospital and Dubbo Base Hospital).

All participants were required sign a written consent prior to their inclusion in the study.

\section{Author details}

${ }^{1}$ NSW Kids and Families, Sydney, Australia. ${ }^{2}$ Public Health Officer Training Program, NSW Ministry of Health, Sydney, Australia. ${ }^{3}$ NSW Office of Preventive Health, Sydney, Australia. ${ }^{4}$ Centre for Population Health, NSW Ministry of Health, Sydney, Australia.

\section{Received: 12 August 2016 Accepted: 24 August 2016}

\section{Published online: 30 August 2016}

\section{References}

1. Gaillard R, Durmus B, Hofman A, Mackenbach JP, Steegers EA, Jaddoe WW Risk factors and outcomes of maternal obesity and excessive weight gain during pregnancy. Obesity. 2013;21(5):1046-55.

2. Mamun AA, Kinarivala M, O'Callaghan MJ, Williams GM, Najman JM, Callaway LK. Associations of excess weight gain during pregnancy with long-term maternal overweight and obesity: evidence from 21 y postpartum follow-up. Am J Clin Nutr. 2010;91(5):1336-41.

3. Stotland NE, Hopkins LM, Caughey AB. Gestational weight gain, macrosomia, and risk of cesarean birth in nondiabetic nulliparas. Obstet Gynecol. 2004;104(4):671-7.

4. Nohr EA, Vaeth M, Baker JL, Sorensen T, Olsen J, Rasmussen KM. Combined associations of prepregnancy body mass index and gestational weight gain with the outcome of pregnancy. Am J Clin Nutr. 2008;87(6):1750-9.

5. Ludwig DS, Currie J. The association between pregnancy weight gain and birthweight: a within-family comparison. The Lancet. 2010;376(9745):984-90.

6. Muktabhant B, Lumbiganon P, Ngamjarus C, Dowswell T. Interventions for preventing excessive weight gain during pregnancy. Cochrane Database Syst Rev. 2012:4:CD007145.

7. Phelan S, Phipps MG, Abrams B, Darroch F, Schaffner A, Wing RR. Practitioner advice and gestational weight gain. J Women's Health 2011;20(4):585-91.

8. Brawarsky P, Stotland NE, Jackson RA, et al. Pre-pregnancy and pregnancyrelated factors and the risk of excessive or inadequate gestational weight gain. Int J Gynaecol Obstet. 2005;91(2):125-31.

9. Giroux I, Lander S, Charlesworth S, Mottola MF. Weight history of overweight pregnant women. Can J Diet Pract Res. 2009;70(3):127-34.

10. Institute of Medicine (US) and National Research Council (US). Committee to reexamine IOM pregnancy weight guidelines. In: Rasmussen KM,
Yaktine $A L$, eds. Weight gain during pregnancy: reexamining the guidelines. Washington (DC); 2009

11. Stotland NE, Cheng YW, Hopkins LM, Caughey AB. Gestational weight gain and adverse neonatal outcome among term infants. Obstet Gynecol. 2006;108:635-43.

12. Dodson E, Kiel D, Boehmer T, Leet T, Artal R. Gestational weight gain and pregnancy outcomes in obese and morbidly obese women: How much is enough? Am J Obstet Gynecol. 2005;193(6):S178.

13. de Jersey SJ, Nicholson JM, Callaway LK, Daniels LA. A prospective study of pregnancy weight gain in Australian women. Aust N Z J Obstet Gynaecol. 2012:52(6):545-51.

14. Chung JG, Taylor RS, Thompson JM, et al. Gestational weight gain and adverse pregnancy outcomes in a nulliparous cohort. Eur J Obstet Gynecol Reprod Biol. 2013;167(2):149-53.

15. Australian Health Ministers' Advisory Council. Clinical practice guidelines: antenatal care - module 1. Canberra: Australian Government Department of Health and Ageing; 2012

16. Brown MJ, Sinclair M, Liddle D, Hill AJ, Madden E, Stockdale J. A systematic review investigating healthy lifestyle interventions incorporating goal setting strategies for preventing excess gestational weight gain. PLoS One. 2012;7(7):e39503.

17. Thangaratinam S, Rogozinska $E$, Jolly $K$, et al. Effects of interventions in pregnancy on maternal weight and obstetric outcomes: meta-analysis of randomised evidence. BMJ. 2012;344:e2088.

18. Cogswell ME, Scanlon KS, Fein SB, Schieve LA. Medically advised, mother's personal target, and actual weight gain during pregnancy. Obstet Gynecol. 1999;94(4):616-22.

19. Jeffries K, Shub A, Walker SP, Hiscock R, Permezel M. Reducing excessive weight gain in pregnancy: a randomised controlled trial. Med J Aust. 2009:191(8):429-33.

20. Phelan S, Jankovitz K, Hagobian T, Abrams B. Reducing excessive gestational weight gain: lessons from the weight control literature and avenues for future research. Womens Health. 2011;7(6):641-61.

21. Soltani H, Duxbury AMS, Arden MA, Dearden A, Furness PJ, Garland C. Maternal obesity management using mobile technology: a feasibility study to evaluate a text messaging based complex intervention during pregnancy. J Obes. 2015;2015:10

22. Dodd JM, Turnbull D, McPhee AJ, et al. Antenatal lifestyle advice for women who are overweight or obese: LIMIT randomised trial. BMJ. 2014;348:g1285.

23. Pampel FC, Krueger PM, Denney JT. Socioeconomic disparities in health behaviors. Annu Rev Sociol. 2010:36:349-70.

24. Goode AD, Reeves MM, Eakin EG. Telephone-delivered interventions for physical activity and dietary behavior change: an updated systematic review. Am J Prev Med. 2012;42(1):81-8

25. O'Hara BJ, Phongsavan P, Venugopal K, et al. Effectiveness of Australia's Get Healthy Information and Coaching Service(R): translational research with population wide impact. Prev Med. 2012;55(4):292-8.

26. Welsby D, Nguyen B, O'Hara BJ, Innes-Hughes C, Bauman A, Hardy LL. Process evaluation of an up-scaled community based child obesity treatment program: NSW Go4Fun(R). BMC Public Health. 2014;14:140.

27. Olander EK, Atkinson L, Edmunds JK, French DP. Promoting healthy eating in pregnancy: what kind of support services do women say they want? Primary Health Care Research \& Development. 2012;13(3):237-43.

28. NSW Kids and Families. Having a baby. Sydney: NSW Ministry of Health; 2012

29. Sports Medicine Australia. Exercise in pregnancy. 2014; http://sma.org.au/ wp-content/uploads/2009/10/WIS-ExPreg.pdf. Accessed on 18 May 2015

30. National Health and Medical Research Council. Australian dietary guidelines. Canberra: National Health and Medical Research Council; 2013.

31. Donner A. Some aspects of the design and analysis of cluster randomization trials. J R Stat Soc: Ser C: Appl Stat. 1998:47(1):95-113.

32. Australian College of Midwives. National midwifery guidelines for consultation and referral. 3rd ed. Australian College of Midwives: 2013

33. Cunningham CE, Teale GR. A profile of body mass index in a large rural Victorian obstetric cohort. Med J Aust. 2013:198(1):39-42.

34. Centre for Epidemiology and Evidence. New South Wales mothers and babies 2010. Sydney: NSW Ministry of Health; 2012

35. McLennan W, Podger AS. National Nutrition Survey: nutrient intakes and physical measurements, Australia, 1995. Australian Bureau of Statistics: 1998

36. Barr M, Baker D, Gorringe M, Fritsche L. NSW Population Health Survey: description of methods. Sydney: NSW Department of Health; 2008. 
37. Wright J, Scott J. The Fat and Fibre Barometer, a short food behaviour questionnaire: reliability, relative validity and utility. Aust J Nutr Diet. 2000;57(1):33-9.

38. Australian Institute of Health and Welfare. The Active Australia Survey: a guide and manual for implementation, analysis and reporting: Australian Institute of Health and Welfare; 2003

39. Smith BJ, Marshall AL, Huang N. Screening for physical activity in family practice: evaluation of two brief assessment tools. Am J Prev Med. 2005;29(4):256-64.

Submit your next manuscript to BioMed Central and we will help you at every step:

- We accept pre-submission inquiries

- Our selector tool helps you to find the most relevant journal

- We provide round the clock customer support

- Convenient online submission

- Thorough peer review

- Inclusion in PubMed and all major indexing services

- Maximum visibility for your research

Submit your manuscript at www.biomedcentral.com/submit 